Revista Iberoamericana, Vol. LXX, Núm. 206, Enero-Marzo 2004, 29-34

\title{
ACÁ EN ROSARIO Y ALLÁ EN EL SUR
}

POR

AngÉLICA GoRodischer

Escritora

Doña Carolina tuvo cinco hijas y cinco hijos, y de esos diez sobrevivieron cinco: cuatro mujeres y un varón. De la mujer y los cuatro varones que murieron, uno fue a los veinte años en Cosquín, tuberculoso, después de una vida turbulenta para decirlo suavemente. Los tres varones y la mujer restantes murieron chiquitos, de escarlatina, fiebre tifoidea, esas cosas de las que se morían los chicos a fines del siglo XIX.

Doña Carolina vivió siempre en Rosario, primero en la calle San Juan cerca del Gas y después en la calle Santa Fe cerca de la Plaza 25 de Mayo. Al Gas llevaban los padres desesperados a sus hijas tísicas a que respiraran hondo porque se decía que ese fluido que servía para iluminar y calentar podía quizá cicatrizarles los pulmones a las pálidas niñas que tomaban vinagre y limón para ser aun más pálidas, casi hasta la transparencia. Los médicos decían que no, que lo único que podía curarlas era una buena alimentación, mucho sol, clima seco y mucho reposo, pero las dejaban ir al Gas porque la medicina es impotente contra las creencias y sobre todo contra el misterio. Por eso, las inmediaciones de la casa de Doña Carolina estaban siempre muy concurridas por carruajes, caballos y gentes de a pie y ella, Doña Carolina, mandaba a una mucama a ver si entre la gente había algunos conocidos, que los había, para invitarlos con té caliente en invierno o limonada fresca en verano.

Ella estaba siempre alerta, era la primera en levantarse, la última en acostarse y su día estaba poblado de actividades, obligaciones y compromisos. La casa era vasta: un frente gris con cochera, puerta doble, dos balcones. Entrada, puerta cancel, recibidor, escritorio, sala, salita más chica y más íntima, comedor de diario, comedor grande; tres patios, el primero de recepción, con bancos andaluces de mayólica, mesas, macetas con plantas, toldo y jaula para los canarios; al segundo daban los dormitorios; al tercero, que tenía veredas de baldosa pero era de tierra, plantas, higuera, pajarera y pileta de lavar, daban la cocina, la antecocina, la despensa y las dependencias de servicio; seis dormitorios, cocina, baño y habitaciones y baño del servicio. Todo bajo su mirada, sin falta.

$\mathrm{Al}$ amanecer casi, recorría la casa y preguntaba y había que contestar a todo lo que preguntaba, quiénes estaban levantadas, a quién se le habían pegado las sábanas y por qué, dónde estaban las listas de enseres y vituallas que hacía falta comprar, si habían llegado o no las cuentas del almacén, la carbonería, la verdulería, la carnicería, qué proponía la cocinera para el almuerzo y la comida de la noche, si el chico de los mandados había ido 
a comprar el diario, si ya habían baldeado la vereda, y así. Después inspeccionaba la cocina y la ropa lavada antes de guardarla para planchar y finalmente se sentaba, en el segundo patio si hacía calor, en el comedor de diario si hacía frío, y tomaba té con leche con tostadas con manteca.

Después se levantaba Don Alberto, que desayunaba en el comedor, leía un poco el diario y se iba al estudio.

Por la mañana Doña Carolina se vestía y salía con alguno de sus hijos o hijas y una mucama para vigilarlos (no había llegado aún el tiempo de las misses), o porque necesitaba comprarles ropa o porque quería ver a alguna de sus hermanas o hacer una visita de no mucho compromiso o hablar con el tapicero o el carpintero o cualquier otra persona que hiciera algún trabajo para su casa.

Pero antes de mediodía estaba de vuelta y controlaba cómo se ponía la mesa, si era para diario o para almuerzo con invitados; y si la comida de los chicos estaba lista, a punto, servida y los chicos con las manos lavadas camino al comedor de diario.

El almuerzo se abría siempre con sopa. El caldo se hacía todos los días, con carne que podía ser falda, rabo, quijada, azotillo, caracú o todo junto; o con gallina, y en todos los casos con verduras y con hierbas para darle gusto. Cuanto más amarillo el caldo, cuanto más espeso, oloroso y lleno de ojos, mejor para la salud. Después de la sopa se servía el segundo que era el principal, carne o pollo o cerdo o cordero acompañado de arroz, papas, choclos o lo que fuera que estuviera de estación; y algún otro plato más liviano: torrejas o tortilla o budín de espinacas o alguna verdura con salsa blanca y gratinada, y si había lugar, se servían también la carne y el acompañamiento que habían sido soporte del caldo. Después venía el postre, gelatina o flan o arroz con leche o mazamorra y finalmente la fruta. En la antecocina, las mucamas, el chico de los mandados y la cocinera comían lo mismo que los patrones. En casa de Doña Carolina no se tomaba ni café ni licores después del almuerzo. Don Alberto se fumaba un cigarro, leía el diario, dormitaba en su sillón y volvía a irse al estudio.

A esa hora a Doña Carolina le daba un sueño atroz. Resistía sin embargo. Los chicos dormían la siesta, el servicio también y el sol de la siesta de verano o la lluviecita de otoño le provocaban unas enormes ganas de acostarse y dormir. No lo hacía. A lo más que llegaba era a recostarse en un sillón gemelo del de Don Alberto y cerrar los ojos un rato. A veces el rato se estiraba y uno de sus chicos o una mucama venían a despertarla porque era necesario que estuviera en alguna parte haciendo algo o dando directivas para más tarde. En ese momento ella se daba cuenta de lo cansada que estaba pero se levantaba y casi corriendo iba a ver qué era lo que pasaba.

Enseguida se ocupaba del cuarto de plancha en el que también se cosía y se remendaba. Había que contar las servilletas y apartarlas por juegos. Había que revisar los manteles para ver si había quedado alguna mancha. Había que aparear las medias, alisar los frentes de las camisas, poner aparte la ropa a almidonar y ver que el almidón ya estuviera listo, ni muy chirle ni muy espeso, extender sobre la mesa la ropa y entresacar la que necesitaba un remiendo, un zurcido o algún arreglo. Poner aparte la que ya no servía para regalarla a la cocinera o a alguna mucama.

Ya había llegado la hora del té. Doña Carolina se acicalaba porque Don Alberto estaba a punto de llegar. Antes de tomar el té con él, se ocupaba de que los chicos tomaran 
el suyo con mucha leche y bien caliente en invierno y que comieran scons y medialunas hechas en casa. Cuando llegaba Don Alberto la mesa para el té estaba puesta en el comedor de diario si no había visitas y en el grande si las había. Para comer, la cocinera había hecho scons, una sandtorte, bocaditos con dulce de membrillo y bombitas de crema y dulce de leche. Don Alberto tomaba el té apurado y volvía a irse al estudio.

La tarde pasaba rápidamente. Doña Carolina hacía visitas o las recibía. Hacia las seis había que supervisar el baño y la comida de los chicos. A las ocho todos tenían que estar en la cama y ella pasaba a darles un beso a cada uno y a contarles un cuentito con moraleja y a rezar con ellos “Ángel de mi guarda, mi dulce compañía...”.

A la noche se tendía la mesa con algo más de pompa, hubiera o no visitas. No se abría la comida con sopa sino con un plato frío: pechugas de pollo con ensalada de papas o rodajas de carne al horno fría con salsa verde. Después venía el plato principal que era más o menos como el del mediodía, y el postre. Quesos, pero no fruta. Y Don Alberto se tomaba una copa de vino clarete. Doña Carolina no: ella no tomaba nunca vino. Sólo una copita de licor cuando sentía el estómago un poco pesado, o media copa de champagne cuando había visitas y para los cumpleaños.

Los domingos eran iguales a los días de semana, sólo que a la mañana Doña Carolina iba a misa con sus hijas, sus hijos y las mucamas. Don Alberto en cambio, se quedaba todo el día en la casa.

El primer lunes del mes era día de recibo y desde las tres de la tarde en adelante se servía té, café, chocolate con masas y tortas, y hacia las seis algunas bebidas fuertes para los señores que llegaban a buscar a sus mujeres o simplemente a saludar y cumplir.

Los miércoles eran tardes de costurero. Doña Carolina se reunía con otras señoras, una vez en casa de cada una, y todas cosían para los pobres.

Para los cumpleaños había una reunión de familia y se le hacían regalos a quien cumplía. Venían, quizá las amigas más cercanas con sus hijas y sus hijos.

Para Nochebuena se armaba el pesebre y había que acostarse temprano porque si los chicos habían sido buenos el Niño Dios pasaba y dejaba sus dones en los zapatos. Al día siguiente iban todos a misa y al almuerzo se comía siempre algo especial.

Doña Carolina murió después de tener su décimo hijo, que fue una hija, a los treinta y tres años, de tuberculosis, una tarde de mayo, muy fría y muy gris.

Doña Pilar tuvo ocho hijos y dos hijas, de los cuales sobrevivieron las dos mujeres y cinco de los varones. Ella vino a este país tan raro, tan distinto de sus Pirineos aragoneses en los que había vivido, primero en Villanueva de Gallo y después en Bujaraloz que era el pueblo de su marido. Allá en donde fueron a vivir, al sur, con el viento omnipresente y un mar duro y gris casi a las puertas de la casa, no había montañas verdes en verano y blancas en invierno ni casitas escondidas en las laderas, ni bosques oscuros, sino una llanura interminable que metía miedo mirar sobre todo en las tardes. Ahí, a ese país rudo cuya única voz parecía ser la del viento, ahí llegó Doña Pilar con sus vestidos negros y su rodete y sus manos curtidas, trayendo una valijita de cartón atada con una piola y un sobre de papel marrón en el que guardaba las fotos amarillentas de la familia que había quedado lejos.

Se fue a vivir a una casa grande, demasiado grande para ellos pero que pronto quedaría chica con los hijos y las hijas que llegarían uno detrás de otro. Se adaptó 
rápidamente: ¡había tanto que hacer! Tanto que no quedaba lugar para el carozo de amargura que le debe haber quedado adentro después del arrancón, el viaje, la llegada, todo lo extraño que encontró en el sur.

Se levantaba antes de que amaneciera, en lo oscuro, sin prender una vela ni una lámpara. Tanteando salía del dormitorio llevando la ropa que se iba a poner apretada contra el cuerpo. Se vestía en el corredor, siempre de negro, con medias negras y suaves zapatillas de fieltro negro en invierno, de lona negra en verano. Soplaba la ceniza sobre las brasas de la noche y avivaba el fuego. Hervía la leche y hervía el agua que había sacado del filtro de piedra y que serviría para tomar. A ella le hubiera gustado hervir también el agua que usaría para cocinar porque el agua sin hervir era dura y le arruinaba la pava y las cacerolas, pero hubiera sido perder el tiempo que se necesitaba para que el agua para tomar cayera gota a gota del cono de piedra al recipiente, de modo que se resignaba.

Preparaba el mate cocido y sacaba el pan de su bolsa de lino y lo cortaba en rebanadas gruesas. Más tarde hornearía más pan en el horno de barro allá afuera, pero el pan del desayuno era pan del día anterior que ella humedecía y ponía cerca del fuego para que quedara tierno.

Don Juan se levantaba ruidosamente, prendía la vela en la mesa de luz, se vestía y aparecía en la cocina cuando el mate cocido y el pan estaban listos sobre la mesa. Una vez que Don Juan se iba, ella tomaba mate cocido y comía del pan tibio. Despertaba a los chicos más grandes y los vestía para la escuela. Los más chicos quedaban en la cuna o lloriqueando se frotaban los ojitos llenos de sueño. Una vez terminados los desayunos, con balde, estropajo, escoba, trapo de piso, jabón y lejía, Doña Pilar limpiaba la casa, toda la casa: las habitaciones, los dos corredores, las baldosas alrededor del patio, el baño, la cocina, el gallinero en el que buscaba huevos, y afuera, la vereda.

Enseguida había que preparar el almuerzo. A media mañana ponía la olla para el caldo y preparaba lo que podría llamarse puchero, que era también un recuerdo de los cocidos de su tierra. Hacía la sopa con fideos grandes y en los platos de los chicos rompía un huevo muy fresco de los que había traído temprano del gallinero. A las doce llegaban todos, cuando ella tenía todo listo y los más chicos jugaban en el patio después de haber tomado su leche y comido sus papillas regadas con jugo de carne.

Doña Pilar no se sentaba a la mesa con su familia: iba y venía con platos y con fuentes, con cucharones y aceiteras y repasadores y cazuelas hasta que Don Juan y los chicos mayores hubieran terminado. Una vez que Don Juan volvía al trabajo, las hijas ayudaban a sacar la mesa y se iban a hacer dormir la siesta a los chiquitos. Doña Pilar se sentaba entonces un ratito sólo un ratito a la mesa y se tomaba un plato de sopa y comía lo que hubiera, sin fijarse mucho en lo que fuera, pensando en lo que tenía que hacer el resto del día.

Que era, a la tarde, ocuparse de la ropa. Destender la que estaba en la soga en la parte de atrás del patio, poner un lienzo limpio sobre la mesa de la cocina y sobre ese lienzo repasar prenda por prenda, pegar botones, cambiar elásticos, coser costuras descosidas, zurcir medias, remendar fundillos y codos, achicar camisas y calzones para que sirvieran a los más chicos. Y enseguida lavar la ropa del día y planchar la que acababa de repasar y arreglar. 
También para Doña Pilar la tarde pasaba rápidamente. A media tarde los chicos tomaban mate cocido y comían pan, con miel si de las quintas le habían regalado algo a Don Juan, o con algún dulce que ella hubiera hecho en esos días. Se hacía noche muy temprano en invierno y muy tarde en verano. Pero con luz o con oscuridad a las ocho la familia estaba de nuevo sentada a la mesa y tomaba su sopa y comía su pan fresco, recién sacado del horno.

A las nueve Don Juan se iba a la cama y las chicas acostaban a sus hermanos mientras Doña Pilar se sentaba a tomar la sopa. Cuado terminaba, antes de lavar platos y vasos y cacerolas y peroles, iba a ver a los chicos y con las yemas de dos dedos les tocaba la frente para darles una bendición silenciosa.

Cuando todos dormían y la casa estaba en silencio, Doña Pilar cubría las brasas con ceniza y despacito se iba a dormir. Se desvestía en el corredor, en lo oscuro, mientras soñaba.

Ella soñaba con comprarse un juego de comedor: una mesa redonda grande; diez sillas y dos más con el respaldo más alto y apoyabrazos para Don Juan y para ella; un aparador con dos puertas y cuatro cajones en el medio para guardar los cubiertos, los dos manteles y las servilletas, los repasadores, y en los espacios de los costados los platos y las fuentes. Y una vitrina. Una vitrina en la que pondría la jarra de vidrio con flores pintadas que había traído de Villanueva en su valijita de cartón envuelta en pañuelos y medias para que no se rompiera, y el juego de té de loza amarilla que le había regalado Don Amancio a la muerte de Doña Paca, cuando él y los dos hijos se habían ido de la casa de al lado. La tetera gorda, la azucarera con su tapa, la lechera y doce tazas con sus platos. Intacto estaba, lo mismo que la jarra, guardado en el estante de abajo del armario del dormitorio. Con eso soñaba Doña Pilar. Para eso ahorraba en una lata oxidada bajo la cocina, de a cinco centavos cada vez que podía sisar del vuelto de la plata que le daba Don Juan para la casa. Algún día se compraría un juego de comedor, algún día.

Los domingos eran iguales a los días de semana salvo que Don Juan se levantaba tarde y se quedaba todo el día en la casa y ella mandaba a las chicas a que llevaran a sus hermanos a misa. Doña Pilar no iba a misa porque no tenía tiempo ni ganas. Se imaginaba que a Dios no le iba a importar que faltara a la iglesia y más, que le iba a parecer bien que se quedara en la casa ocupada en la cocina y la pileta.

No había festejos de cumpleaños. Enriqueta, la mayor de las hijas, trajo del colegio la novedad de que había que festejar los cumpleaños y empezó a preguntar qué día de qué año había nacido cada uno. Pero Don Juan dijo que se dejaran de tonterías, aunque Doña Pilar siempre sospechó que Enriqueta había guardado las fechas en la memoria y que en secreto las hijas tenían una suerte de festejo del que ni ella ni su marido se enteraban.

Un día Doña Pilar se encontró con que el puñado de monedas de cinco centavos que había ido acumulando llegaba a sumar cuarenta pesos. Cuarenta pesos en monedas de cinco centavos. Llevó el paquetito de monedas a la verdulería de Don Lino y él se las cambió, asombrado, en billetes de diez pesos. Con esos cuatro billetes Doña Pilar compró un juego de comedor que tenía una mesa grande, ovalada y no redonda pero a ella le dio igual, doce sillas, un aparador con tapa de mármol y una vitrina con tres estantes de vidrio y espejo en la que puso la jarra pintada y el juego de té de loza amarilla. Lo hizo poner en la habitación grande del frente, enceró bien el piso y cerró la puerta para que no entrara 
tierra ni suciedad. Cuando todos estaban en otra parte, Don Juan en el trabajo y los chicos en la escuela, Doña Pilar abría la puerta, entraba, miraba su juego de comedor, se sentaba en una silla, después en otra y en otra, abría los cajones y las puertas del aparador, se paraba frente a la vitrina y después se iba, cerrando otra vez la puerta.

Los chicos crecieron y dos de los varones salieron a esquilar y con la paga compraron ovejas y les fue bien. Compraron más ovejas y después un campito y al poco tiempo un campo más grande y de pronto Doña Pilar tuvo una casa más grande en el centro de la ciudad, con luz eléctrica y agua caliente y calefacción, y sus hijos compraron camiones para el campo y un auto para Don Juan. Los hijos le dijeron que iban a contratar mujeres de servicio para que ella dejara de trabajar en la casa, pero Doña Pilar no quiso. Transó sólo con una lavandera, pero siguió cocinando y limpiando aun cuando la vida le iba cambiando tan aceleradamente.

La vida podía cambiar, es cierto, pero Doña Pilar siguió vistiéndose de negro y peinándose con rodete, y nunca quiso vender el juego de comedor para comprar otro más fino, más moderno, como querían sus hijas.

Murió a los sesenta y ocho años, del corazón, casi sin darse cuenta, como había vivido, seria, menuda, fuerte, el carozo de pena allá adentro y la bendición en las yemas de los dedos.

De: Historia de mi Madre (inédito) 